\title{
Pengembangan Produk Unggulan Daerah Tembakau Asepan Klaten
}

\author{
Sutaryono ${ }^{1}$, Sholikhah Deti A $^{1}$, Arie Rachma Putri ${ }^{2}$, Endang Wahyuningsih ${ }^{3}$ \\ ${ }^{1}$ Program Studi Farmasi, Sekolah Tinggi Ilmu Kesehatan Muhammadiyah Klaten \\ ${ }^{2}$ Akademi Akutansi Muhammadiyah Klaten \\ ${ }^{3}$ Program Studi Kebidanan, Sekolah Tinggi Ilmu Kesehatan Muhammadiyah Klaten \\ Email : sutaryono@stikesmukla.ac.id
}

\begin{abstract}
Abstrak
Tembakau Asepan merupakan salah satu produk unggulan Kabupaten Klaten yang potensi sebagai sumber pendapatan asli daerah dan penyerapan tenaga kerja. Namun produksi tembakau saat ini cenderung menurun, karena kualitas tembakau yang dihasilkan petani tidak sesuai dengan standar mutu. Oleh karena itu tujuan pendampingan mitra ini adalah memberikan pelatihan kepada mitra petani tembakau untuk meningkatkan hasil yang bermutu, difusi ipteks di bidang teknologi pengolahan, perbaikan manajemen produksi dan pemasaran. Metode pelaksanaan pengembangan mitra kelompok tani perkebunan tembakau asepan "Tani Mandiri" desa Wonosari, Trucuk, Kabupaten melalui kolaborasi Tim perguruan tinggi, mitra, mahasiswa dan dukungan pembiayaan dari Direktorat Riset dan Pengabdian Masyarakat Direktorat Jenderal Riset dan Pengembangan Kementerian Riset dan Teknologi / Badan Riset dan Inovasi Nasional. Kegiatan yang dilakukan meliputi difusi ipteks di bidang teknologi budidaya tembakau, manajemen mitra dan strategi pemasaran hasil produksi. Hasil kegiatan yang sudah terlaksana antara lain; 1 ) mengadakan sosialisasi dan pelatihan kepada mitra yang bertujuan agar mitra dapat menghasilkan produksi yang memenuhi standar mutu meliputi pola tanam dari pembibitan, budidaya, pemupukan, pestisida dan pasca panen dilaksanakan pada tanggal 18 sd 19 Juli 2020 dengan mematuhi protokol kesehatan. 2) Pengadaan peralatan mesin cultivator untuk mengolah tanah yang mampu membuat efisiensi biaya operasional usaha sebesar $37,5 \%$ dibandingkan dengan pengolahan secara manual, 3) mitra telah mampu melakukan perbaikan manajemen dengan membuat pembukuan keuangan dan sarana inventory box yang baik, 4) memfasilitasi link kerjasama mitra dalam pemasaran hasil produksinya dengan perusahaan importir tembakau Alliance One Indonesia. Kata Kunci: Tembakau asepan, mitra tani mandiri, mutu, manajemen, pemasaran
\end{abstract}

\section{Abstract \\ Asepan tobacco is one of the superior products of Klaten Regency as a source of income} and employment. However, current tobacco production tends to decline, because the quality of tobacco produced by farmers is not in accordance with quality standards. Therefore the aim of this partner assistance is to provide training to tobacco farmer partners to improve quality results, diffusion of science and technology in processing technology, improve production management and marketing. The method of implementation in the development of asepan tobacco plantation farmer group partners or known as "Tani Mandiri" in Wonosari village, Trucuk, Regency through collaboration of college teams, partners, students and financial support from the Directorate of Research and Community Service, Directorate General of Research and Development, Ministry of Research and Technology / National Research and Innovation Agency. Activities carried out include science and technology diffusion in the field 
of tobacco cultivation technology, partner management and marketing strategies for production products. The results of activities that have been carried out include; 1) holding outreach and training with the aim that partners can produce products that meet quality standards including cropping patterns from seedling, cultivation, fertilization, pesticides and post harvest held on 18-19 July 2020 in compliance with health protocols. 2) Procurement of cultivator machine equipment to cultivate the soil with an efficiency of business operating costs of $37.5 \%$ compared to manual processing 3) improvement of partner management related to good financial bookkeeping and inventory box facilities, 4) facilitating partners' collaboration links in marketing with tobacco importer company Alliance One Indonesia.

Keywords : Asepan tobacco, Mitra Mandiri, Quality, Management, Marketing.

\section{PENDAHULUAN}

Arah kebijakan dan prioritas pembangunan daerah Kabupaten Klaten diarahkan pada penguatan potensi lokal yang berorientasi pada peningkatan kesejahteraan masyarakat. Kebijakan ini akan mendorong potensi masyarakat lokal dan menumbuhkan produk-produk unggulan daerah untuk berkompetisi secara nasional. Produk unggulan daerah Kabupaten Klaten yaitu batik, lurik, konveksi, tembakau asepan dan rajangan, mebel, keramik, dan logam. Produk Tembakau Asepan sejak tahun 2016 telah ditetapkan sebagai produk unggulan daerah Kabupaten Klaten sesuai SK Bupati No 050/84 Tahun 2016, (Pemkab Klaten, 2018).

Wilayah Kabupaten Klaten sangat potensial untuk dikembangkan sebagai perkebunan tembakau, karena sebagian besar wilayahnya merupakan lahan yang subur dengan debit air yang baik, disertai dengan iklim yang cocok untuk tanaman perkebunan tembakau. Ada beberapa daerah sebagai penghasil tembakau, antara lain untuk tembakau asepan meliputi 9 kecamatan dengan jumlah petani 5256 orang luas areal $1060 \mathrm{Ha}$, dan tembakau rajang 4 kecamatan dengan jumlah petani 3840 orang luas areal $674 \mathrm{Ha}$, (BPS Klaten, 2018)

Komoditas tembakau dari segi ekonomi sebagai sumber pendapatan asli daerah dan dari segi sosial sangat berperan dalam penyerapan tenaga kerja secara intensif, oleh karena itu industri tembakau sebagai produk unggulan strategis Kabupaten Klaten yang sangat menjanjikan. Namun produksi tembakau selama lima tahun terakhir sangat fluktuatif dan cenderung turun. Pada tahun 2015 produksi tembakau asepan kering 1164,27 ton pada tahun 2016 turun menjadi 1038,53 ton/Ha, untuk tembakau rajangan dari 2219.485 ton menjadi 825,04 ton $^{1)}$. Ada beberapa faktor yang menyebabkan penurunan produksi tersebut, diantaranya adalah menurunnya luas areal tanam, musim yang tidak menentu, manajemen usaha tani kurang optimal dan kualitas tidak sesuai dengan standar mutu tembakau, (BPS Klaten, 2018; Nuryati et.al.,2005)

Banyak faktor yang harus diperhatikan dalam menghasilkan mutu tembakau antara lain faktor tanah, iklim, pemupukan dan cara panen, (Ali, M. 2015). Mutu tembakau yang tidak sesuai standar kualitas sulit masuk ke perusahaan, sehingga petani tembakau mengalami kerugian. Rendahnya mutu tembakau disebabkan adanya keterbatasan kelompok tani tembakau terhadap pemahaman dan pengetahuan terkait (a)teknologi pola tanam pembibitan, budidaya, penggunaan pupuk dan pestisida (b)Peningkatan efisiensi pada pengolahan tembakau yang lebih modern (c)Penerapan konsep manajemen dan pemasaran yang benar.

Melalui program pengabdian masyarakat Pengembangan Produk Unggulan Daerah (PPUD) ini mendorong mitra kelompok tani perkebunan tembakau asepan "Tani Mandiri" 
yang berlokasi di desa Wonosari, Trucuk, Kabupaten Klaten yang telah memproduksi tembakau 5 tahun. Hasil penelitian terdahulu yang telah dilakukan pada petani tembakau asepan di Wonosari, Trucuk hasil penerimaan lebih besar daripada total biaya dengan nilai $\mathrm{R} / \mathrm{C}$ ratio $1,51>1$, namun dari segi ekonomi belum efisiensi terutama penggunaan pupuk dan pestisida, (Nur, Apriana, 2013). Hasil observasi juga menunjukkan bahwa mutu produksi antar petani tidak merata karena pengetahuan pola tanam dari pembibitan, budidaya, pemupukan, pestisida dan pasca panen antar petani berbeda-beda, belum memiliki alat produksi yang memadai, sehingga perlu peralatan pendukung untuk menjamin mutu dan meningkatkan produksi, belum ada penjaminan mutu (SOP) dalam proses produksinya, sehingga kualitas produk bervariasi, kurang tertib dalam pembukuan serta pasar penjualan terbatas lokal melalui model pengepul, reseller belum berkelompok (KUKB). Oleh karena itu secara umum tujuan Program Pengembangan Produk Unggulan Daerah tembakau asepan Kabupaten Klaten Provinsi Jawa Tengah adalah untuk mengembangkan mitra yang telah memproduksi tembakau asepan agar dapat mewujudkan produk unggulan, secara khusus tujuan kegiatan ini adalah; 1) meningkatkan pengetahuan mitra untuk menghasilkan mutu bahan baku tembakau yang berkualitas, tentang pola tanam dari pembibitan, budidaya, pemupukan, pestisida dan pasca panen. 2) Meningkatkan teknologi peralatan pendukung untuk menjamin mutu dan meningkatkan produksi mitra. 3) Meningkatkan kemampuan mitra dalam manajemen pengelolaan usaha tembakau dan 4) Meningkatkan penguasaan mitra dalam pemasaran hasil produksi tembakau.

\section{BAHAN DAN METODE}

Pelaksanaan pengembangan mitra kelompok tani perkebunan tembakau asepan "Tani Mandiri" desa Wonosari, Trucuk, Kabupaten melalui kolaborasi Tim perguruan tinggi dan Program Pengembangan Produk Unggulan Daerah dari Direktorat Riset dan Pengabdian Masyarakat Direktorat Jenderal Riset dan Pengembangan Kementerian Riset, Teknologi, dan Pendidikan Tinggi Dirjen Pendidikan Tinggi Kementerian Pendidikan Nasional. Tim dosen yang terlibat dalam PPPUD ini adalah 4 orang dari 4 kompetensi yang berbeda dengan bidang keahlian serta melibatkan 8 mahasiswa. Pelaksanaan kegiatan ini selama delapan (8) bulan yaitu dari bulan Maret 2020 sampai Oktober 2020.

Kegiatan diawali dengan sosilaisasi dan mengadakan pelatihan pola tanam tembakau dari cara pembibitan, penggunaan pupuk dan pestisida dan pengolahan pasca panen yang dilaksanakan yang bertujuan untuk menghasilkan mutu produksi berkualitas. Pendekatan alih tehnologi dengan pengadaan peralatan mesin cultivator untuk mengolah tanah. Perbaikan manajemen mitra dengan implementasi konsep pembukuan dan pengadaan Inventory box. Untuk membantu mitra dalam pemasaran dengan menfasilitasi mitra membangun link atau jaringan pemasaran dengan distributor tembakau.

\section{HASIL DAN PEMBAHASAN}

Tembakau asepan merupakan hasil produksi mitra Kelompok Tani Perkebunan "Tani Mandiri" yang berlokasi di desa Wonosari, Trucuk, Kabupaten Klaten, melalui proses pengolahan dengan pengasapan (open) menggunakan bahan bakar kayu. Mitra telah memiliki badan usaha dari Menteri Hukum dan Hak Asasi Manusia RI no. AHU0078786.AH.01.07 tahun 2016. Mitra ini sangat didukung oleh Asosiasi Petani Tembakau Indonesia dan diperkuat dengan SK Bupati No 050/84 Tahun 2016, produk tembakau asepan sebagai produk unggulan Kabupaten Klaten. 
Pendampingan PPUD ini diawali dengan kegiatan sosialisasi dan pelatihan budidaya tanaman tembakau. Sesuai permasalahan mitra yang dihadapi terkait dengan mutu kualitas bahan baku dari petani yang berbeda-beda maka pelatihan bertujuan untuk meningkatkan pengetahuan petani tentang pola tanam dari pembibitan, budidaya, pemupukan, pestisida dan pasca panen. Pelatihan dilaksanakan pada tanggal 18 sd 19 Juli 2020 dengan mematuhi protokol kesehatan yang ketat. Narasumber pelatihan tersebut antara lain dari petugas penyuluh pertanian Kecamatan Trucuk, Asosiasi Petani Tembakau Indonesia (APTI) Klaten, PT AOI atau alliance One Indonesia dan Arie Rachma Putri, SE, M.Sc. Direktur Akademi Akuntansi Muhammadiyah Klaten.

Implementasi dari kegiatan ini terlihat bahwa petani pada musim tanam saat ini sudah menerapkan pola tanam tembakau yang seragam, dalam pembibitan petani menggunakan metode metode Pot tray yang awalnya dengan pembibitan metode bedengan. Metode pot tray ini lebih efisiensi tempat, pemeliharan mudah bisa dirumah, irigasi dengan pengairan dan penanaman langsung tumbuh, sementara kalau metode bedengan memerlukan lahan khusus di sawah, irigasi dan saat pemindahan bibit mengalami stress sekitar 6 hari. Aplikasi pemupukan petani sudah mengurangi penggunaan pupuk dan pestisida kimia, dengan menggantikan organik. Sesuai grade atau screening perusahaan, hasil produksi tembakau yang bisa masuk adalah yang sesuai standar diantaranya kualitas, warna, ketebalan, rendemen nikotin, dan tidak mengandung bahan-bahan kimia, (Tirtosastro et.al, 2004; Sutaryono, et al, 2018).

Hasil lain kegiatan pendampingan PPUD ini adalah adanya perbaikan manajemen mitra terutama terkait dengan pembukuan, dan sarana inventory box. Mitra sudah menyusun pembukuan baik aktivitas usaha maupun keuangan. Semua aktivitas tercatat dengan baik khususnya arus kas keluar masuk keuangan, dan semua pembukuan sudah tersimpan dengan baik dan rapi di brankas inventaris. Adanya pembukuan yang baik ini mitra dapat melihat dan menganalisis keuntungan usahanya.

Difusi teknologi yang diberikan kepada mitra dengan pengadaan peralatan mesin cultivator untuk mengolah tanah. Sebelum ada PPUD mitra dalam pengolahan tanah menggunakan tenaga cangkul manual. Analisis kebutuhan biaya tenaga untuk pengolahan tanah dengan cangkul manual, setiap luas $2000 \mathrm{~m} 2$ membutuhkan 5 orang dengan upah Rp. 80.000 , selama 2 hari sehingga total pengeluaran Rp. 800.000,. Saat ini mitra sudah menggunakan mesin cultivator untuk mengolah tanah, dengan biaya setiap luas $2000 \mathrm{~m} 2$ sebesar Rp. 300.000,- hanya dalam waktu 4 jam. Hal ini membuktikan dengan adanya program pendampingan ini mampu membuat efisiensi biaya operasional usaha sebesar $37,5 \%$.

Program pendampingan ini juga memfasilitasi mitra dalam metode pemasaran hasil produksinya, selama ini mitra dan anggota masih melakukan pemasaran secara individu dan atau melalui tengkulak. Dengan adanya PPUD mitra sudah mempunyai link jaringan pemasaran yaitu perusahaan importir PT. Aliance One Indonesia. Namun demikian perusahaan tetap memberikan persyaratan hasil produksi mitra harus memenuhi standar atau grade yang telah disepakati, oleh karena itu agar kerjasama ini dapat berlanjut terus mitra harus menjaga kepercayaan dan mutu hasil produksi yang berkualitas.

\section{KESIMPULAN DAN SARAN}

Kesimpulan pelaksanaan kegiatan pengabdian masyarakat pengembangan produk unggulan daerah antara lain: 
1. Telah mengadakan sosialisasi dan pelatihan yang bertujuan agar mitra dapat mengimplementasikan pola tanaman tembakau yang memenuhi standar mutu.

2. Difusi tehnologi dengan pengadaan peralatan mesin cultivator untuk mengolah tanah yang mampu membuat efisiensi biaya operasional usaha sebesar $37,5 \%$

3. Perbaikan manajemen mitra terkait pembukuan keuangan dan sarana inventory box yang baik.

4. Memfasilitasi link kerjasama mitra dalam pemasaran hasil produksinya dengan perusahaan importir tembakau

Upaya tindak lanjut kegiatan pengabdian masyarakat ini dapat disarankan ;

1. Perlu implementasi SOP dalam setiap kegiatan agar hasil produksi tembakau asepan yang memenuhi standar mutu

2. Pendampingan manajemen mitra dalam pembukuan yang berorientasi pada Komputerisasi akuntansi keuangan

3. Untuk dilanjutkan pemanfaatan sarana dan prasarana alat mesin cultivator, curring dan inventory box yang diperoleh

4. Perlu disusun draf kerjasama kesepakatan dengan perusahaan dalam pemasaran hasil produksi

\section{UCAPAN TERIMA KASIH}

Terimakasih kepada Direktorat Riset dan Pengabdian Masyarakat Direktorat Jenderal Riset dan Pengembangan Kementerian Riset dan Teknologi / Badan Riset dan Inovasi Nasional yang telah mendanai kegiatan pengembangan produk unggulan daerah ini dan Lembaga Penelitian dan Pengabdian STIKES Muhammadiyah Klaten, petugas penyuluh pertanian lapangan kecamatan Trucuk, asosiasi petani tembakau indonesia (APTI) dan PT. Aliance One Indonesia yang telah mendukung terlaksananya kegiatan pengabdian ini.

\section{DAFTAR PUSTAKA}

Ali, M. (2015). Pengaruh Dosis Pemupukan Npk Terhadap Produksi Dan Kandungan Capsaicin Pada Buah Tanaman Cabe Rawit (Capsicum Frutescens L.). Jurnal Agrosains: Karya Kreatif Dan Inovatif, 2(2), 171-178.

BPS Klaten, Klaten dalam Angka 2018, https://klatenkab.go.id/klaten-dalam-angka/

Isti Nuryati, Masyuri, Dwijono Hadi Darwanto, 2005, Analisis Efisiensi Usaha Tani Tembakau Jawa Asapan di Desa Wonosari Kecamatan trucuk Kabupaten Klaten, Agro Ekonomi, Fakultas Pertanian Gadjah Mada Yogyakarta

Pemkab Klaten, 2018, Rencana Kerja Pemerintah Daerah Kabupaten Klaten Tahun 2019, Pemerintah Kabupaten Klaten.

Sutaryono, Hartono, Ari Probandari, Prabang Setyono, 2018, Dampak Paparan Asap Rokok Lingkungan Rumah Tangga Terhadap Residu Nikotin Debu, Urine Cotinine, Dan Peningkatan Gejala Asma Pada Anak, Disertasi, Uns

Tirtosastro, S., Gatot Kartono dan Suharto. 2004. Pengelolaan tembakau virginia di daerah pengembangan baru Kabupaten Blitar. Kerjasama Penelitian Badan penelitian dan Pengembangan pertanian dan PT. Sadana Arifnusa.

Yudha Hadian Nur, Devi Apriana, Daya Saing Tembakau Virginia Lokal Di Pasar Dalam Negeri, Buletin Ilmiah Litbang Perdagangan, Vol.7 No.1, Juli 2013 


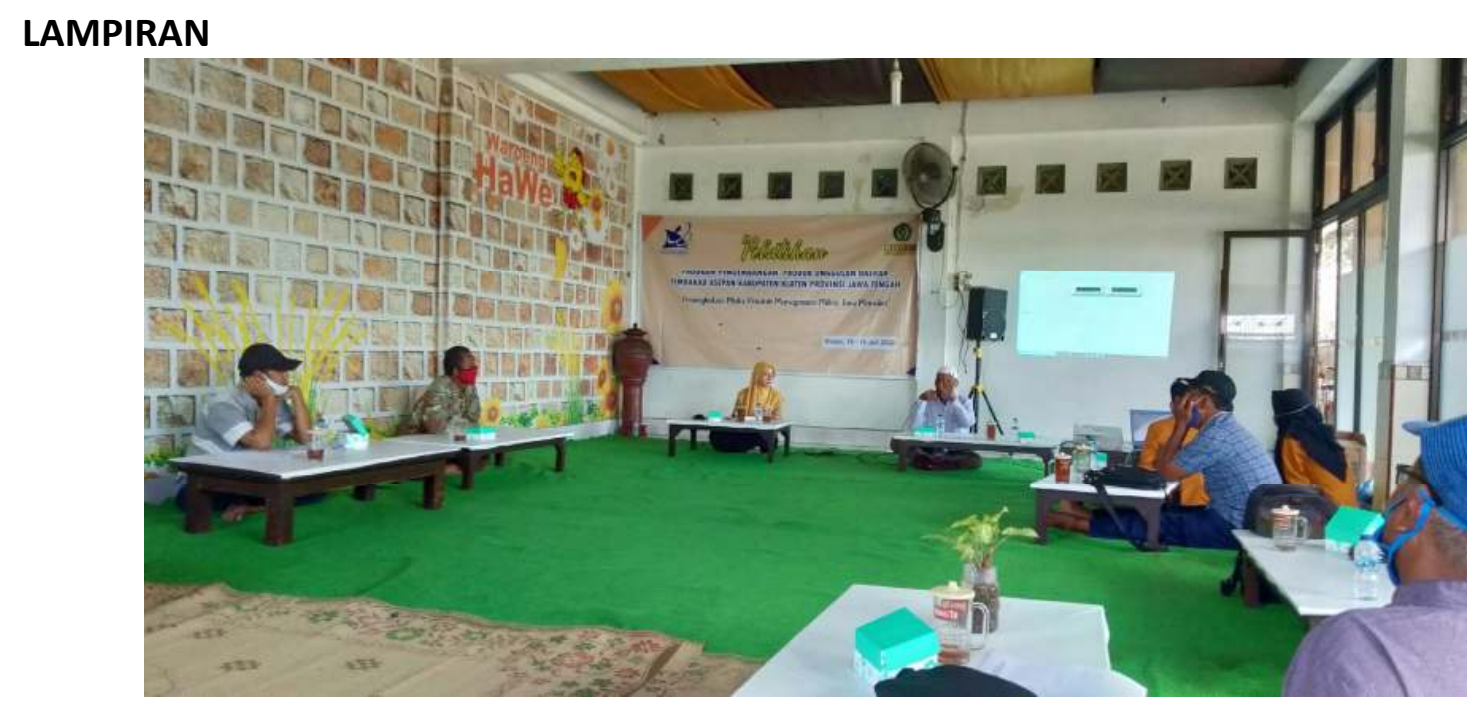

Gambar 1. Pelatihan Budidaya Tembakau

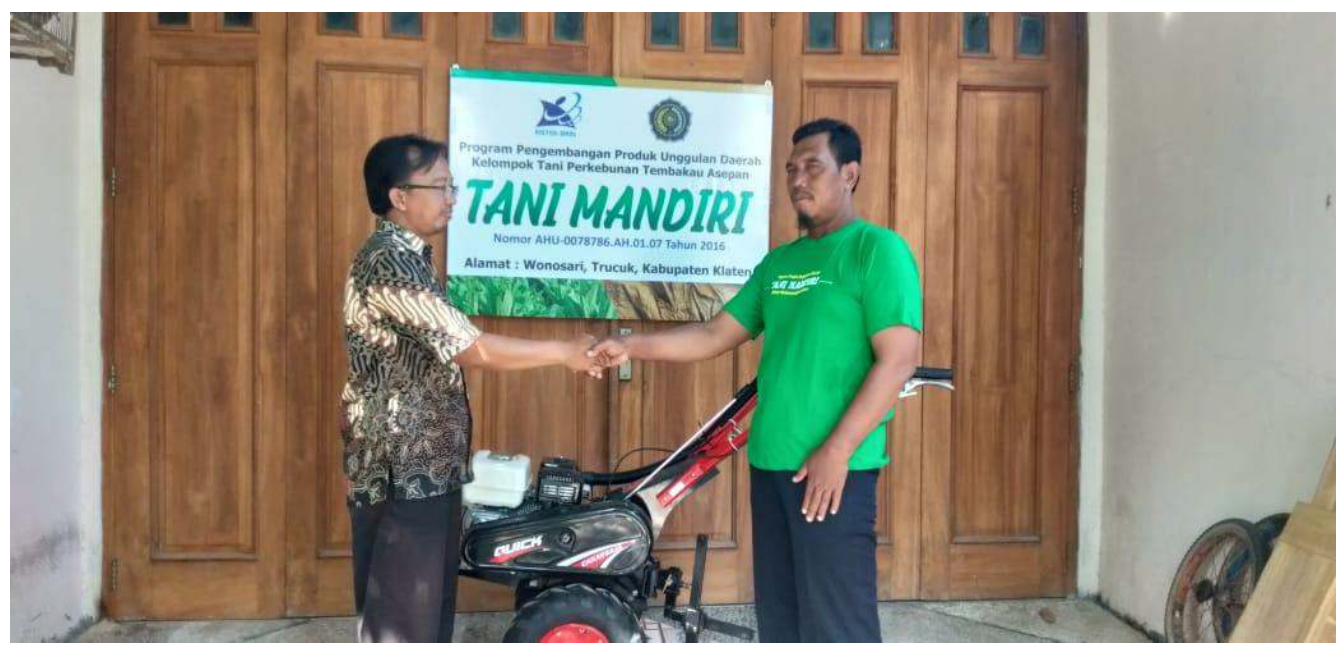

Gambar 2. Penyerahan alat Cultivator ke Mitra

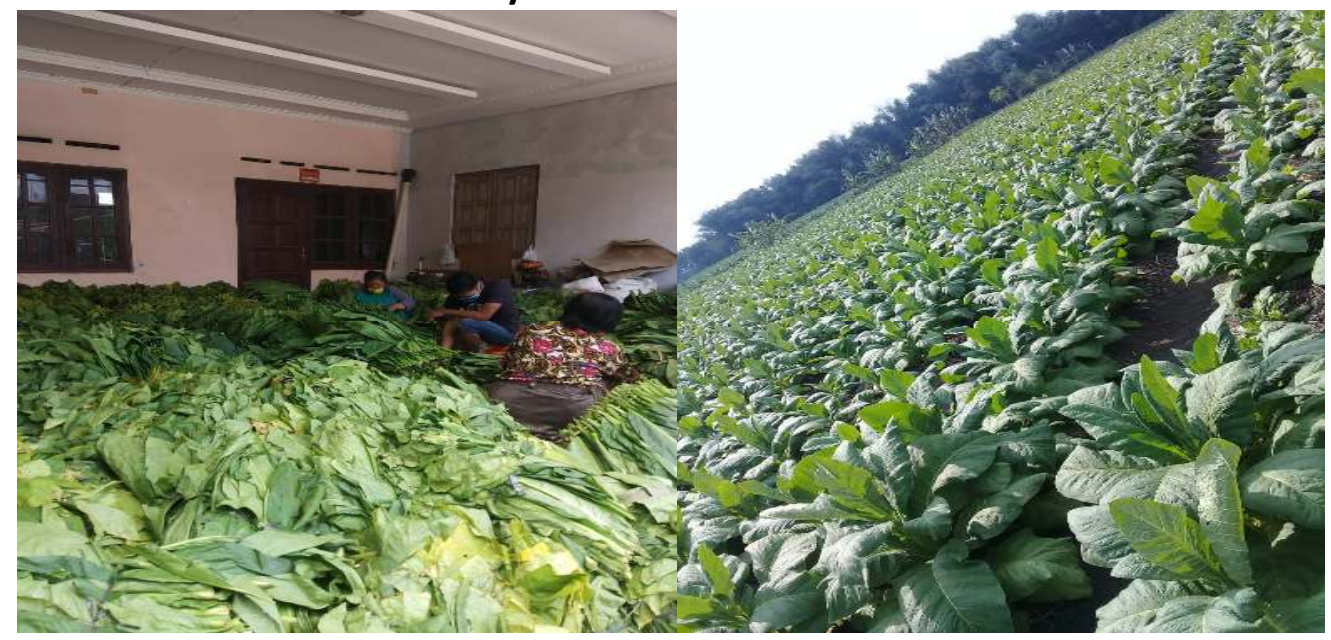

Gambar 2. Hasil Produksi Budidaya Tembakau 